\title{
Introduction to the new FKM guideline which considers nonlinear material behaviour Melanie Fiedler ${ }^{* 1}$, Michael Vormwald ${ }^{I}$
}

${ }^{1}$ Materials Mechanics Group, Technische Universität Darmstadt, D-64285 Darmstadt, Germany

\begin{abstract}
In 2018 the German Research Association of Mechanical Engineering (FKM) will present a new guideline for calculating the fatigue crack initiation life of structures and components .

The user of this guideline

... is able to calculate the fatigue life for crack initiation for structures of steel, cast steel and aluminium alloy

... has to perform an elastic FE-calculation and gets the quality of an elastic-plastic calculation

$\ldots$ is able to determine the cyclic material parameters and the damage parameter Wöhler curve by the ultimate tensile strength $R_{m}$ $\ldots$ is able to calculate the fatigue life in HCF and LCF for constant and variable amplitude loading

This paper presents the algorithms of the new guideline, gives an overview about the mechanical background and discusses the results for specimens of steel and aluminium alloys. It also shows results comparing the new to the current FKM guideline for a given steel structure.
\end{abstract}

\section{Introduction}

The Research Association of Mechanical Engineering (FKM) is a cooperating network of German industry and research to identify and solve current mechanical problems in industry. During the last years various guidelines have been published by the FKM in order to improve the competitiveness of the small and mediumsized industry. The FKM guideline for calculating the fatigue life of structures of steel or aluminium for the failure criteria fracture is available for a couple of years [1]. Currently a new guideline which accounts for the nonlinear material behaviour in the fatigue life calculation for failure criteria crack initiation is going to be released.

\subsection{The FKM guideline for fracture}

The fatigue part of the FKM guideline [1] lead the user through a calculation of the fatigue live for fracture of a structure of steel or aluminium alloy based on stresses according to the Theory of Elasticity. For steel, the FKM guideline proposes a Wöhler curve with an exponent of $k=5$ and a fatigue limit for a fatigue life of $N_{D}=10^{6}$.

$$
\sigma_{B K}=\sigma_{A K} \cdot\left(\frac{N_{D}}{N_{B K}}\right)^{1 / k}
$$

The amplitude for the fatigue limit $\sigma_{A K}$ depends on the material, the geometry and the stress ratio of a constant amplitude loading, see [1].

\subsection{The FKM guideline for crack initiation}

The fatigue part of the new guideline is based on the Local Strain Approach (LSA) [2]. Using standard algorithms of the LSA linear elastically calculated stresses and strains in a notched area are transformed to elastic-plastic stresses and strains using approximation formulas. Based on these elastic-plastic stresses and strains, the stress-strain-curves for a given loading sequence can be simulated and the damage effect for the structure can be predicted using damage parameters and a damage accumulation rule. The basic material parameters used in describing the cyclic stress-strainbehaviour and the damage parameter Wöhler curves can be estimated applying simple approximation methods which only require input of the ultimate tensile strength $R_{m}$ and the material group.

\section{The algorithms of the new guideline}

\subsection{Cyclic stabilized stress strain curves}

The material behaviour under cyclic loading can be described by the cyclic stabilized stress-strain curve by Ramberg-Osgood [3]

$$
\varepsilon=\frac{\sigma}{E}+\left(\frac{\sigma}{K^{\prime}}\right)^{\frac{1}{n^{\prime}}}
$$

Hysteresis loop branches are described using Masing's law [4]:

$$
\varepsilon=\frac{\sigma}{E}+2 \cdot\left(\frac{\sigma}{2 K^{\prime}}\right)^{\frac{1}{n^{\prime}}}
$$

with material parameters $E, K^{\prime}$ and $n^{\prime}$. Using an approach by Wächter [5] Young's modulus $E$ can be set to $206000 \mathrm{MPa}$ for steel and $70000 \mathrm{MPa}$ for aluminium alloy. Wächter also proposes the FKM method to estimate the cyclic material parameters $K^{\prime}$ and $n^{\prime}$ based on the ultimate tensile strength.

$$
K^{\prime}=\frac{a_{\sigma} \cdot\left(\frac{R_{m}}{\mathrm{MPa}}\right)^{b_{\sigma}}}{\left(\min \left(\varepsilon_{\text {limit }}, a_{\varepsilon} \cdot\left(\frac{R_{m}}{\mathrm{MPa}}\right)^{b_{\varepsilon}}\right)\right)^{n^{\prime}}}
$$

For $n^{\prime}, a_{\varepsilon}, b_{\varepsilon}, a_{\sigma}, b_{\sigma}, \varepsilon_{\text {limit }}$ see Table 1 .

Table 1 : Constants for cyclic stabilized stress strain curve [5]

\begin{tabular}{|c|c|c|c|}
\hline $\begin{array}{l}\text { Material } \\
\text { group }\end{array}$ & Steel & Cast iron & $\begin{array}{l}\text { Aluminium } \\
\text { alloy }\end{array}$ \\
\hline$n^{\prime}$ & 0.187 & 0.176 & 0.128 \\
\hline$a_{\sigma}$ & 3.1148 & 1.732 & 9.12 \\
\hline$b_{\sigma}$ & 0.897 & 0.982 & 0.742 \\
\hline$a_{\varepsilon}$ & 1033 & 0.847 & 895.9 \\
\hline$b_{\varepsilon}$ & -1.235 & -0.181 & -1.183 \\
\hline$\varepsilon_{\text {limit }}$ & 0.338 & $\infty$ & $\infty$ \\
\hline
\end{tabular}




\subsection{Flow curves}

Flow curves connect the loading of the structure or the elastically calculated stresses with the elastic plastic strains in the notched area, see [6, 7]. Two different approximation formulas for flow curves are presented in the new guideline.

\subsubsection{Flow curve by Neuber}

The approach by Neuber [8] is a simple approach for a flow curve. It connects the elastic stresses $\sigma_{e}$ with the elastic-plastic stresses and strains $\sigma, \varepsilon$ using the limit load factor $K_{p}$.

$$
\varepsilon=\frac{\sigma_{e}}{\sigma} \cdot K_{p} \cdot e^{*}
$$

The strains $e^{*}$ can be calculated with

$$
e^{*}=\frac{\sigma_{e} / K_{p}}{E}+\left(\frac{\sigma_{e} / K_{p}}{K^{\prime}}\right)^{\frac{1}{n^{\prime}}}
$$

\subsubsection{Flow curve by Seeger and Beste}

The approach by Seeger and Beste [6] is another approach for a flow curve with a better fitting for the high strain area where the strains are mainly plastic. It also connects the elastic stresses $\sigma_{e}$ with the elasticplastic stresses and strains $\sigma, \varepsilon$ using the limit load factor $K_{p}$.

$$
\begin{gathered}
\varepsilon=\frac{\sigma}{E} \cdot\left[\left(\frac{\sigma_{e}}{\sigma}\right)^{2} \cdot \frac{2}{u^{2}} \cdot \ln \left(\frac{1}{\cos (u)}\right)-\frac{\sigma_{e}}{\sigma}+1\right] \\
\cdot\left(\frac{e^{*} \cdot E \cdot K_{p}}{\sigma_{e}}\right)
\end{gathered}
$$

With

$$
u=\frac{\pi}{2} \cdot\left(\frac{\sigma_{e} / \sigma-1}{K_{p}-1}\right)
$$

And using (6) for $e^{*}$.

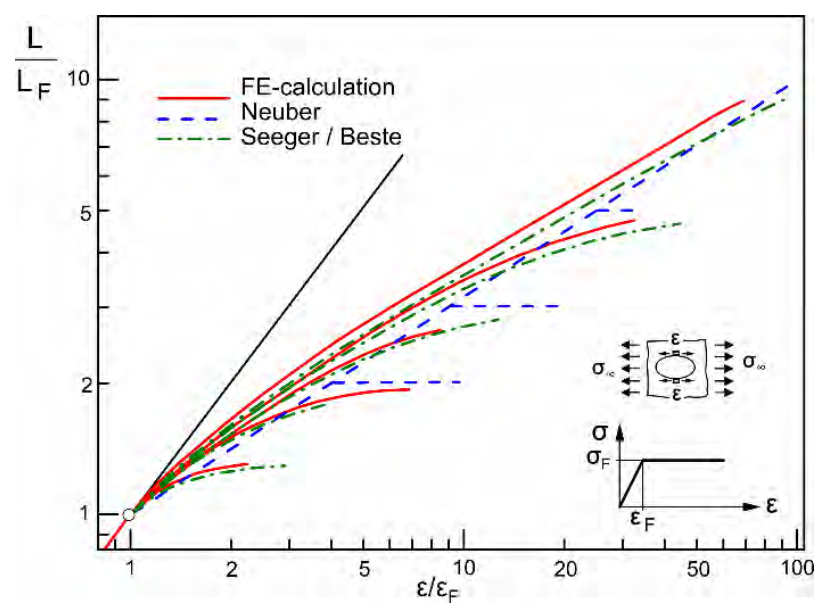

Figure 1 : Comparison of FE-calculation results with flow curves [9]
Fig. 1 shows the difference between the approximation formulas by Neuber and by Seeger and Beste compared with FE-results based on linear elastic ideal plastic material behaviour for a sample of notched plates.

\subsection{Hysteresis Counting Method (HCM)}

The stress-strain-path in the notched area has to be simulated for the whole loading sequence to identify the damage effects. The HCM algorithm as described by Clormann [10] is used in the new guideline to simulate the elastic-plastic stress-strain-path, identify closed hysteresis loops and calculate the required parameters for the damage accumulation. This algorithm is able to distinguish between the initial and reloading stabilized stress-strain-curve and considers the 3 memory effects.

\subsection{Damage Parameter Wöhler curve}

\subsubsection{Damage parameter $P_{R A M}$}

The damage parameter Wöhler curve is based on the material group and the ultimate tensile strength $R_{m}$, see $[5,11]$. The grid point $P_{R A M, Z}$ for the damage parameter Wöhler curve can be calculated using

$$
P_{R A M, Z}=\frac{a_{P, Z}}{f_{R A M}} \cdot\left(\frac{R_{m}}{\mathrm{MPa}}\right)^{b_{P, Z}}
$$

for $a_{P, Z}$ and $b_{P, Z}$ see Table 2, for factor $f_{R A M}$ which includes size effects and a safety concept see [11].

Table 2 : Constants for the $P_{R A M}$ Wöhler curve [5]

\begin{tabular}{|c|c|c|c|}
\hline $\begin{array}{l}\text { Material } \\
\text { group }\end{array}$ & Steel & Cast iron & $\begin{array}{l}\text { Aluminium } \\
\text { alloy }\end{array}$ \\
\hline$d_{1}$ & -0.302 & -0.289 & -0.238 \\
\hline$d_{2}$ & -0.197 & -0.189 & -0.167 \\
\hline$a_{P, Z}$ & 20 & 25.56 & 16.71 \\
\hline$b_{P, Z}$ & 0.587 & 0.519 & 0.537 \\
\hline
\end{tabular}

The damage parameter Wöhler curve is described by:

$$
N_{C I}=10^{3} \cdot \begin{cases}\left(\frac{P_{R A M}}{P_{R A M, Z}}\right)^{\frac{1}{d_{1}}}, & P_{R A M} \geq P_{R A M, Z} \\ \left(\frac{P_{R A M}}{P_{R A M, Z}}\right)^{\frac{1}{d_{2}}}, & P_{R A M}<P_{R A M, Z}\end{cases}
$$

\subsubsection{Damage parameter $P_{R A J}$}

The damage parameter Wöhler curve is based on the material group and the ultimate tensile strength $R_{m}$. The reference point $P_{R A J, Z}$ for the damage parameter Wöhler curve can be calculated using 


$$
P_{R A J, Z}=\frac{a_{P, Z}}{f_{R A J}} \cdot\left(\frac{R_{m}}{\mathrm{MPa}}\right)^{b_{P, Z}}
$$

for $a_{P, Z}$ and $b_{P, Z}$ see Table 3 .

Table 3 : Constants for the $P_{R A J}$ Wöhler curve [5]

\begin{tabular}{|c|c|c|c|}
\hline $\begin{array}{l}\text { Material } \\
\text { group }\end{array}$ & Steel & Cast iron & $\begin{array}{l}\text { Aluminium } \\
\text { alloy }\end{array}$ \\
\hline$d$ & -0.56 & -0.66 & -0.61 \\
\hline$a_{P, Z}$ & 1.173 & 10.03 & 101.7 \\
\hline$b_{P, Z}$ & 1 & 0.695 & 0.26 \\
\hline$a_{P, D}$ & 3.33 & 5.25 & 5.18 \\
& $\cdot 10^{-5}$ & $\cdot 10^{-6}$ & $\cdot 10^{-7}$ \\
\hline$b_{P, D}$ & 1.55 & 1.63 & 2.04 \\
\hline
\end{tabular}

Considering the actual fatigue limit $P_{R A J, D}$ (25) the damage parameter Wöhler curve is described by:

$$
N_{C I}=\left\{\begin{aligned}
\left(\frac{P_{R A J}}{P_{R A J, Z}}\right)^{\frac{1}{d}}, & P_{R A J} \geq P_{R A J, D} \\
\infty, & P_{R A J}<P_{R A J, D}
\end{aligned}\right.
$$

The fatigue limit for the mechanical short crack $P_{R A J, D, 0}$ can be described by

$$
P_{R A J, D, 0}=\frac{a_{P, D}}{f_{R A J}} \cdot\left(\frac{R_{m}}{\mathrm{MPa}}\right)^{b_{P, D}}
$$

for $a_{P, D}$ and $b_{P, D}$ see Table 3 for $f_{R A J}$ which includes size effects and a safety concept see [11].

\subsection{Damage Parameter $P_{R A M}$ and $P_{R A J}$}

In the new guideline two different damage parameters $P_{R A M}$ and $P_{R A J}$ can be used for calculating the fatigue life for crack initiation.

\subsubsection{Damage parameter $P_{R A M}$}

The damage parameter $P_{R A M}$ is based on Smith, Watson and Topper's [12] approach, modified by an approach to respect the material dependent mean stress sensitivity by Bergmann [13].

$$
\begin{aligned}
& P_{R A M}= \\
& \left\{\sqrt{\left(\sigma_{a}+k \cdot \sigma_{m}\right) \cdot E \cdot \varepsilon_{a}}\right.
\end{aligned}
$$

In Bergmann [13] $k$ is material depending but not specified for the material groups, in the new guideline the parameter $k$ is described by

$$
k= \begin{cases}M_{\sigma} \cdot\left(M_{\sigma}-2\right), & \sigma_{m} \geq 0 \\ \frac{M_{\sigma}}{3} \cdot\left(\frac{M_{\sigma}}{3}+2\right), & \sigma_{m}<0\end{cases}
$$

with mean stress sensitivity $M_{\sigma}$ as defined in [1]

$$
M_{\sigma}=a_{M} \cdot 10^{-3} \cdot \frac{R_{m}}{\mathrm{MPa}}+b_{M}
$$

with material group specific parameters $a_{M}$ and $b_{M}$.

\subsubsection{Damage parameter $P_{R A J}$}

The damage parameter $P_{R A J}$ has a fracture mechanics background and considers the influence of crack opening and closing and the loading sequence, see [14]. These effects $[15,16]$ can be considered by using effective stresses and strains, adapting the crack opening strain and reducing the fatigue limit with increasing damage during variable amplitude loading.

\section{Using effective parameters}

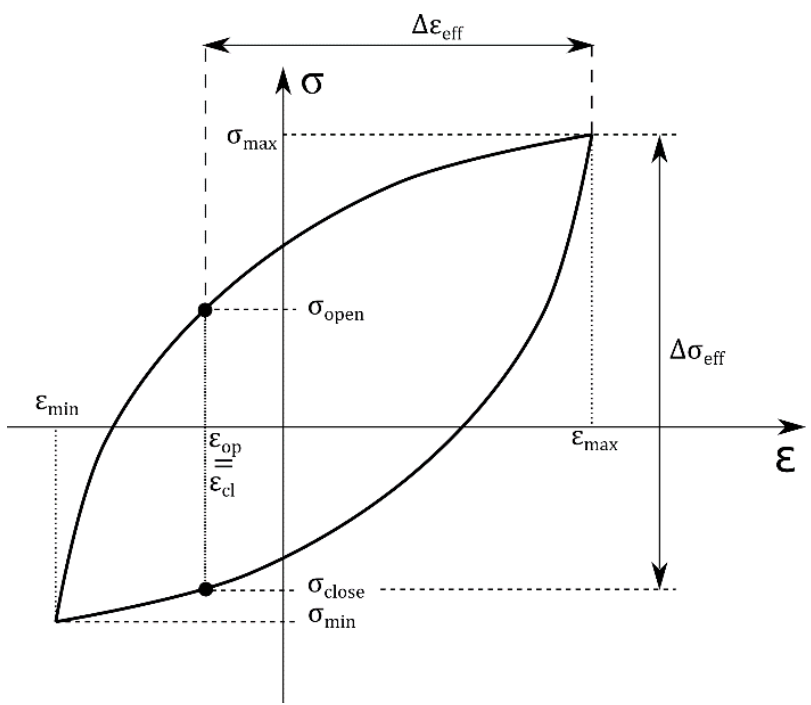

Figure 2 : Effective parameters of a hysteresis loop

The $P_{R A J}$ uses effective stresses and strains when calculating the damage effect of a hysteresis loop. The effective parameters are illustrated in Figure 2, where $\sigma_{\text {open }}$ and $\varepsilon_{o p}$ are the crack opening stress and strain and $\sigma_{\text {close }}$ and $\varepsilon_{c l}$ the crack closure stress and strain. The effective stresses and strains, $\Delta \sigma_{\text {eff }}$ and $\Delta \varepsilon_{\text {eff }}$, are calculated for an open crack, the influence of the hysteresis parameters for a closed crack is neglected. The damage parameter is formulated as

$$
P_{R A J}=\left[\begin{array}{c}
1.24 \cdot \frac{\left(\Delta \sigma_{\text {eff }}\right)^{2}}{\mathrm{E}}+\frac{1.02}{\sqrt{\mathrm{n}^{\prime}}} \cdot\left(\Delta \sigma_{\mathrm{eff}}\right) \cdot \\
\cdot\left(\left(\Delta \varepsilon_{\mathrm{eff}}\right)-\frac{\left(\Delta \sigma_{\mathrm{eff}}\right)}{\mathrm{E}}\right)
\end{array}\right]
$$

with $E, K^{\prime}$ and $n^{\prime}$ see section 2.1 . The crack opening stress is determined by an approach of Newman [17] with

$$
\sigma_{\text {open }}= \begin{cases}\sigma_{\text {max }} \cdot\left(A_{0}+A_{1} \cdot R+A_{2} \cdot R^{2}+A_{3} \cdot R^{3}\right), & R \geq 0 \\ \sigma_{\text {max }} \cdot\left(A_{0}+A_{1} \cdot R\right), & R<0\end{cases}
$$


For constants $A_{i}$ see [11].

\section{Adapting the crack opening strain}

For constant amplitude loadings the crack opening strain can be determined using the ascending hysteresis arm by $\varepsilon_{\mathrm{op}, \mathrm{const}}=\varepsilon_{\mathrm{cl}, \mathrm{const}}=\varepsilon_{\mathrm{min}}+\frac{\left(\sigma_{\mathrm{open}}-\sigma_{\mathrm{min}}\right)}{\mathrm{E}}+2 \cdot\left(\frac{\sigma_{\mathrm{open}}-\sigma_{\mathrm{mi}}}{2 \cdot \mathrm{K}^{\prime}}\right.$

For variable amplitude loadings the sequence effects of the loading history has to be taken into account when calculating the crack opening strain. Therefore, four different strains have to be defined: $\varepsilon_{o p, c o n s t}$, for a fictitious constant amplitude loading using (19), $\varepsilon_{\text {op, hist }}$ for the influence of history of the former hysteresis loops, $\varepsilon_{\text {max,old,hy }}$ and $\varepsilon_{\text {min,old,hy }}$ for the maximum and minimum strain of all former hysteresis loops and $\varepsilon_{\text {max,old,sq }}$ and $\varepsilon_{\text {min,old,sq }}$ for the maximum and minimum strain of all former loading points.

Four different effects has to be considered: 3 For $\varepsilon_{\max } \leq \varepsilon_{o p, h i s t}$ is $\quad \varepsilon_{\text {open }}=\varepsilon_{o p, \text { hist }}$

4 a) For $\varepsilon_{\text {max,old,hy }}<\varepsilon_{\text {max,old,sq }}$ is $\varepsilon_{\text {open }}=\varepsilon_{\text {op,const }}$

b) For $\varepsilon_{\text {min,old,hy }}>\varepsilon_{\text {min,old,sq }}$ is $\varepsilon_{\text {open }}=\varepsilon_{\text {op,const }}$

3. For $\varepsilon_{\text {op,const }}>\varepsilon_{\text {op,hist }}$ is $\varepsilon_{\text {open }}=\varepsilon_{\text {op, hist }}$

4. For $\varepsilon_{\text {op,const }} \leq \varepsilon_{\text {op, hist }}$

a) For $\sigma_{a} \geq 0.4 \cdot \sigma_{F}$ is $\varepsilon_{\text {open }}=\varepsilon_{\text {op,const }}$

b) For $\sigma_{a}<0.4 \cdot \sigma_{F}$ is $\varepsilon_{\text {open }}=\varepsilon_{\text {op,hist }}$

For specific case $\varepsilon_{\min } \geq \varepsilon_{\text {open }}$ the crack opening stress is $\sigma_{\text {open }}=\sigma_{\min }$ and $\Delta \sigma_{\text {eff }}=\sigma_{\max }-\sigma_{\min }$, $\Delta \varepsilon_{\text {eff }}=\varepsilon_{\max }-\varepsilon_{\min }$ when using (17).

Else for $\varepsilon_{\min }<\varepsilon_{\text {open }}$ the crack opening stress is determined by

$$
\varepsilon_{\text {max }}-\varepsilon_{\text {open }}=\frac{\Delta \sigma_{\text {eff }}}{E}+2 \cdot\left(\frac{\Delta \sigma_{\text {eff }}}{2 K^{\prime}}\right)^{1 / n^{\prime}}
$$

with $\Delta \sigma_{\text {eff }}=\sigma_{\max }-\sigma_{\text {open }}$ and $\quad \Delta \varepsilon_{\text {eff }}=\varepsilon_{\max }-$ $\varepsilon_{\text {open }}$ when using (17).

For case 3 with $\varepsilon_{o p, c o n s t}>\varepsilon_{o p \text {,hist }}$ the crack opening strain history needs to be updated by

$$
\begin{gathered}
\varepsilon_{\text {op }, \text { hist }}=\varepsilon_{\text {op,const }}-\left(\varepsilon_{\text {op,const }}-\varepsilon_{\text {open }}\right) \cdot \exp (15 \\
\left.\cdot N_{C I}^{-1}\right)
\end{gathered}
$$

with $N_{C I}$ the fatigue life for the current hysteresis loop calculated by (12). For any other case, the new history crack opening strain is

$$
\varepsilon_{\text {op, hist }}=\varepsilon_{\text {open }}
$$

\section{Decreasing the fatigue limit}

A mechanical short crack length $a_{0}$ has to be determined using material constants $m$ and $C$, the crack length for crack initiation $a_{\text {end }}=0.5 \mathrm{~mm}$ and the grid point of the damage parameter Woehler curve $P_{R A J, Z}$.

$$
a_{0}=\left(a_{\text {end }}^{1-m}-(1-m) \cdot C \cdot P_{R A J, Z}^{m}\right)^{\frac{1}{1-m}}
$$

$C$ can be determined using an approach by [14] with

$$
C=10^{-5} \cdot\left(5 \cdot 10^{5}\right)^{m} \cdot(E)^{-m}
$$

and $m=-\frac{1}{d}$ while $d$ is the exponent of the damage parameter Woehler curve. During the loading sequence, the mechanical short crack opens and closes and growths until the crack length $a_{\text {end }}$ is achieved. This effect is taken into account in the calculation of the decreasing fatigue limit $P_{R A J, D}$ with

$$
\begin{gathered}
P_{R A J, D}= \\
\Delta J_{\text {eff,th }} \cdot\left(\left(\left(a_{\text {end }}^{1-m}-a_{0}^{1-m}\right) \cdot D+a_{0}^{1-m}\right)^{\frac{1}{1-m}}\right. \\
\left.+\frac{\Delta J_{\text {eff }, t h}}{P_{R A J, D, 0}}-a_{0}\right)^{-1}
\end{gathered}
$$

which is equivalent to the consequent Miner rule with actual damage sum $D$. The threshold for the effective $\Delta J$ can be approximated by

$$
\Delta J_{e f f, t h}=\frac{E}{\left(5 \cdot 10^{6} \mathrm{MPa}\right)}
$$

\subsection{Damage Accumulation Rule}

\subsubsection{Damage parameter $P_{R A M}$}

The damage accumulation rule for variable amplitude loading is equivalent to the Miner rule.

$$
D=\sum_{i} \frac{n_{i}}{N_{C I, i}}
$$

Each loading sequence has to be calculated for a second time to close all possible hysteresis loops. Therefore the damage sums of first $D_{1}$ and second run $D_{2}$ can differ. A factor $x$ has to be calculated by

$$
x=\frac{1-D_{1}}{D_{2}}
$$

To calculate the fatigue life for crack initiation with

$$
N_{C I}=(1+x) \cdot H_{0}
$$




\subsubsection{Damage parameter $P_{R A J}$}

The damage accumulation rule for variable amplitude loading is equivalent to a consequent Miner rule. First of all, the maximal possible $P_{R A J}$ and the fatigue limit for crack initiation $P_{R A J, D, e}$ has to be determined and 200 classes have to be created.

$$
\frac{P_{R A J, \text { max }, \text { class }}}{P_{R A J, 1}}=\frac{P_{R A J, 1}}{P_{R A J, 2}}=\cdots=\frac{P_{R A J, 199}}{P_{R A J, D, e}}
$$

Second, the actual fatigue limit $P_{R A J, D}$ has to be classified within this 200 classes.

$$
P_{R A J, q-1} \leq P_{R A J, D}<P_{R A J, q}
$$

Third, with the class index $q$ the amount of cycles to crack initiation after the second run through the loading sequence $N_{-2}$ can be determined using

$$
\begin{aligned}
& f(j)= \\
& \frac{a_{0}^{1-m}-\left[\left(\frac{\Delta J_{e f f, t h}}{P_{R A J, j}}+\frac{\Delta J_{e f f, t h}}{P_{R A J, D, 0}}\right)-a_{0}\right]^{1-m}}{a_{0}^{1-m}-a_{\text {end }}^{1-m}}
\end{aligned}
$$

Last, the fatigue life for crack initiation can be calculated by

$$
N_{C I}=2 \cdot H_{0}+N_{-2}
$$

with the scope of the hysteresis collective $H_{0}$ from the second run through the loading sequence.

\subsection{Extension of the new guideline to fracture}

The new guideline in the current version is only approved to calculate the fatigue life for crack initiation. A first and simple approach to calculate the fatigue life for fracture $N_{F r}$ based on the fatigue life for crack initiation $N_{C I}$ is the U-concept.

The U-concept was determined on a database with more than 1000 datasets for steel. It simply shifts the fatigue life for crack initiation based on damage parameter $P_{R A J}$ using

$$
N_{F r}=U \cdot N_{C I}^{1.15}
$$

With

$$
=\left\{\begin{array}{c}
37.4 \cdot\left(\frac{\sigma_{a}-\sigma_{m}}{R_{m}}\right)^{5} \cdot|R| \geq 0.85, R \leq-1 \\
0.93 \cdot e^{-3.7 R} \cdot\left(\frac{\sigma_{a}+\sigma_{m}}{R_{m}}\right)^{4} \geq 0.42, R>-1
\end{array}\right.
$$

\section{Results}

During a former FKM project a large structural database with results and datasets for crack initiation and fracture fatigue life experiments was build. The database called DaBef [18] was the basis for the following calculation results for constant (CA) and variable amplitude (VA) loadings.

\subsection{Samples with constant amplitude loading}

480 datasets are available for notched geometries of steel under constant amplitude loading in DaBef. Table 4 gives an overview about the range of the datasets. Calculation results with damage parameter $P_{\mathrm{RAJ}}$ in contrast to the experimental results are illustrated in Figure 3. For the calculation results the crack initiation was set to $a_{\text {end }}=0.5 \mathrm{~mm}$, for experimental results the criteria for crack initiation differs between the different references stored in DaBef. In addition there are results for stress- and strain-controlled experiments and also for tension and bending experiments combined in this figure, which explain the range between experimental and calculated fatigue lives, see [19] for comparable results. No safety concept was applied on the calculation results.

Table 4 : Experimental datasets for CA for crack initiation

\begin{tabular}{|l|l|l|l|}
\hline $\begin{array}{l}\text { Material } \\
\text { group }\end{array}$ & $\begin{array}{l}\text { Ultimate } \\
\text { tensile } \\
\text { strength } \\
R_{m}[\mathrm{MPa}]\end{array}$ & $\begin{array}{l}\text { Elastic stress } \\
\text { concentration } \\
\text { factor } K_{t}[-]\end{array}$ & Stress ratio $R$ \\
\hline Steel & $476-1136$ & $1.49-22.2$ & $-1, \ldots, 0.33$ \\
\hline
\end{tabular}

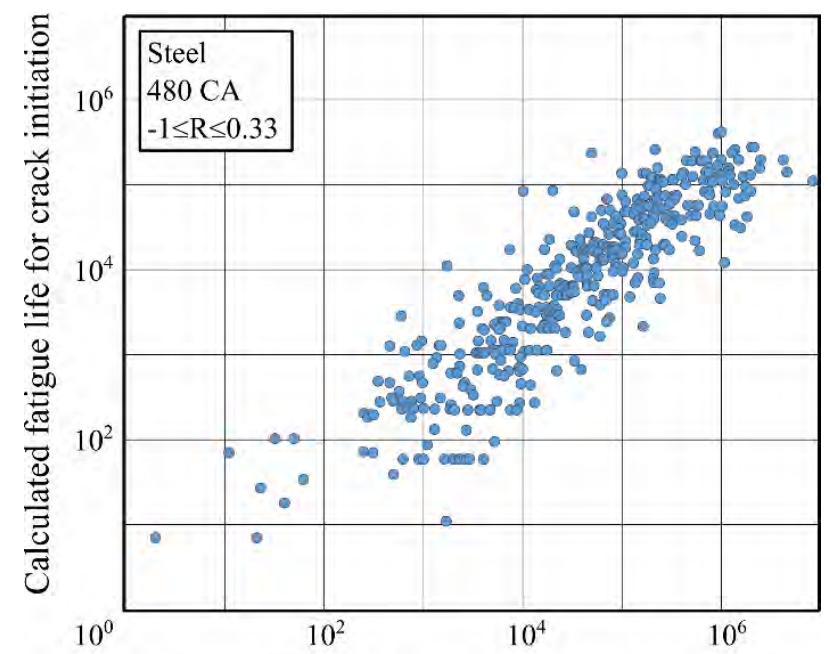

Experimental fatigue life for crack initiation 
Figure 3 : Experimental vs. calculation results for steel calculated with $P_{R A J}$ for crack initiation and constant amplitude loading

Extending the calculation with the U-concept, the calculation results show a good accordance with the experimental results from DaBef, see Figure 4. For fracture the failure criteria hardly differs between the different references of DaBef in contrast to the failure criteria for crack initiation. The range between calculated and experimental results is smaller although 1097 experimental datasets for notched structures of steel were included. Based on this results one could argue that the calculated fatigue life for crack initiation also have a good accuracy compared with experimental results if all experimental results would have been obtained accurately applying the same failure criterion as used in the numerical approach. Figure 5 compares the experimental results with calculation results using the FKM guideline for fracture.

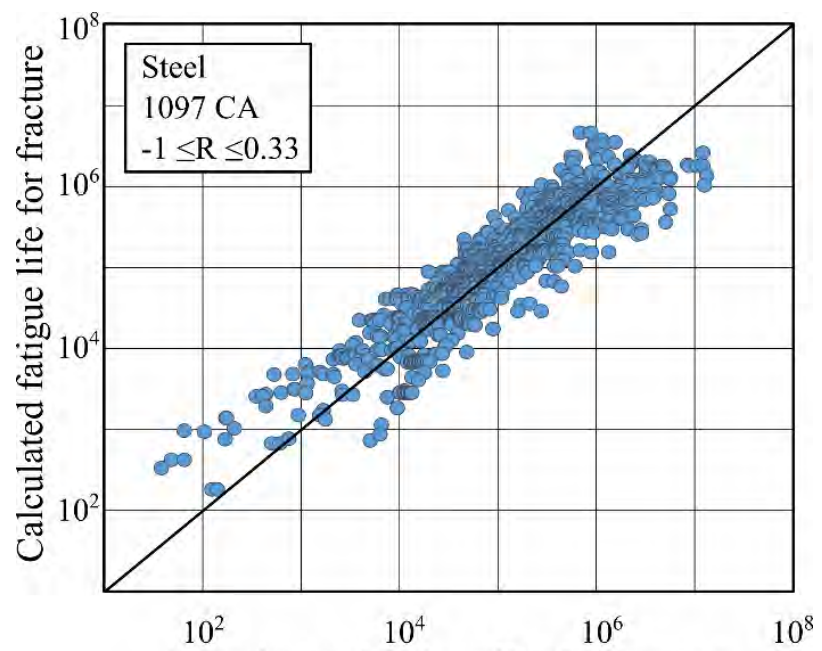

Experimental fatigue life for fracture

Figure 4 : Experimental vs. calculation results for steel calculated with $P_{R A J}$ for fracture and constant amplitude loading

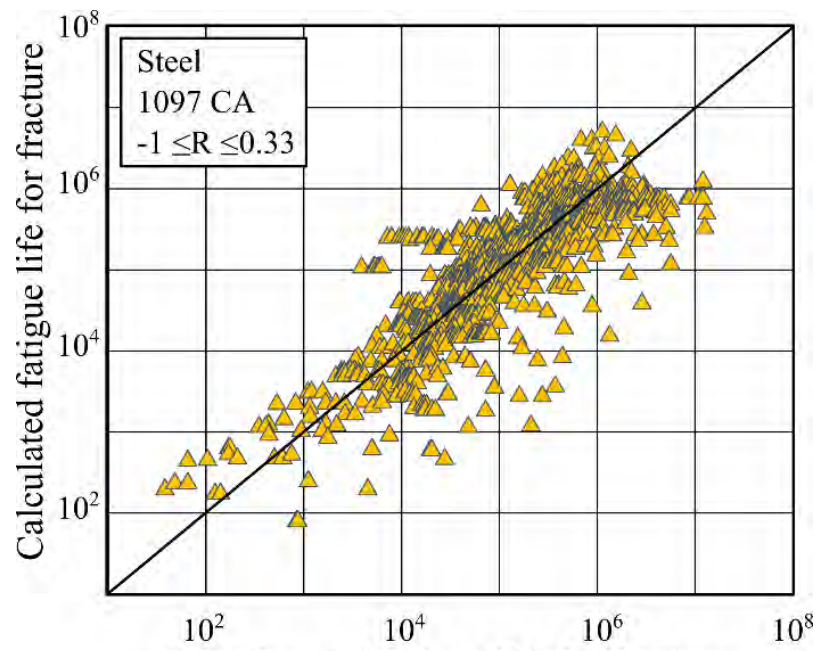

Experimental fatigue life for fracture

Figure 5 : Experimental vs. calculation results for steel calculated with FKM guideline for fracture

Table 5 : Experimental datasets for CA for fracture

\begin{tabular}{|l|l|l|l|}
\hline $\begin{array}{l}\text { Material } \\
\text { group }\end{array}$ & $\begin{array}{l}\text { Ultimate } \\
\text { tensile } \\
\text { strength } \\
R_{m}[\mathrm{MPa}]\end{array}$ & $\begin{array}{l}\text { Elastic stress } \\
\text { concentration } \\
\text { factor } K_{t}[-]\end{array}$ & Stress ratio $R$ \\
\hline Steel & $476-1136$ & $1.01-22.2$ & $-1, \ldots, 0.33$ \\
\hline
\end{tabular}

\subsection{Samples with variable amplitude loading}

360 structural datasets are available in DaBef [18] with structures under variable amplitude loading for failure criteria crack initiation, see Table 6.

Table 6 : Experimental datasets for VA for crack initiation

\begin{tabular}{|l|l|l|l|}
\hline $\begin{array}{l}\text { Material } \\
\text { group }\end{array}$ & $\begin{array}{l}\text { Ultimate } \\
\text { tensile } \\
\text { strength } \\
R_{m}[\mathrm{MPa}]\end{array}$ & $\begin{array}{l}\text { Elastic stress } \\
\text { concentration } \\
\text { factor } K_{t}[-]\end{array}$ & Stress ratio $R$ \\
\hline Steel & $544-935$ & $1.49-3.48$ & $-1, \ldots, 0$ \\
\hline
\end{tabular}

Figure 6 shows calculation versus experimental results. Again the range between experimental and calculation results is higher than expected because of the large difference in the experimental conditions. Figure 7 shows calculation versus experimental results for the failure criteria fracture with 657 experimental datasets, see Table 7. Again there is a better accordance between experimental and calculated fatigue lives for fracture compared with crack initiation. With a life variance $T_{N}$ defined as

$$
T_{N}=\frac{\left(\frac{N_{\text {exp }}}{N_{\text {calc }}}\right)_{90 \%}}{\left(\frac{N_{\text {exp }}}{N_{\text {calc }}}\right)_{10 \%}}
$$

The variance for the results for calculations with variable amplitude loadings is $T_{N}=6.49$ and the mean value is $m=3.79$. The results for variable amplitude loadings for fracture were calculated with $P_{R A J, D, 0}=0.001$ so the fatigue limit were neglected.

Table 7 : Experimental datasets for VA for fracture

\begin{tabular}{|l|l|l|l|}
\hline $\begin{array}{l}\text { Material } \\
\text { group }\end{array}$ & $\begin{array}{l}\text { Ultimate } \\
\text { tensile } \\
\text { strength } \\
R_{m}[\mathrm{MPa}]\end{array}$ & $\begin{array}{l}\text { Elastic stress } \\
\text { concentration } \\
\text { factor } K_{t}[-]\end{array}$ & Stress ratio $R$ \\
\hline Steel & $544-1097$ & $1.01-3.48$ & $-1, \ldots, 0$ \\
\hline
\end{tabular}




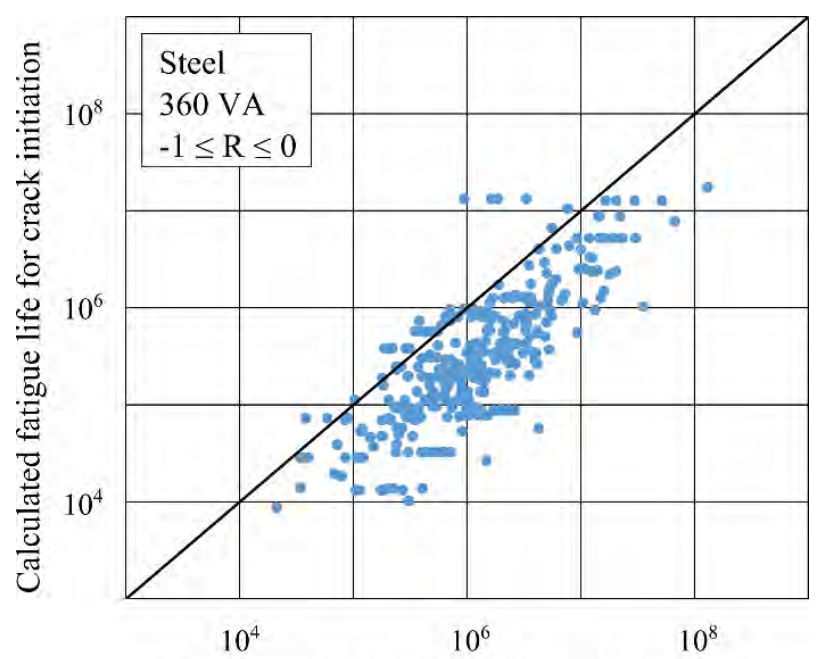

Experimental fatigue life for crack initiation

Figure 6 : Experimental vs. calculation results for steel calculated with $P_{R A J}$ for crack initiation and variable amplitude loading

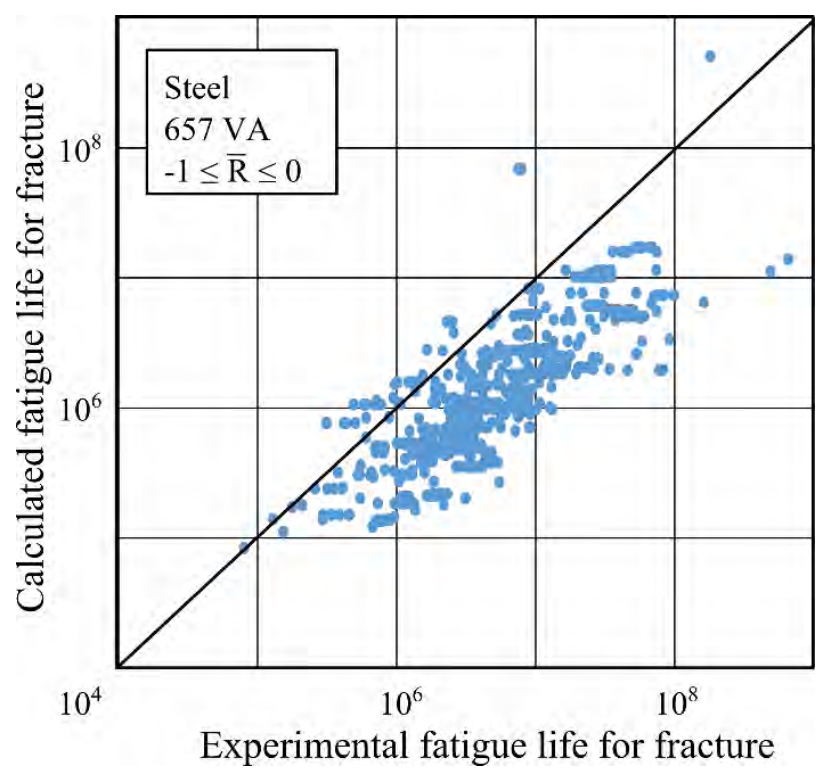

Figure 7 : Experimental vs. calculation results for steel calculated with $P_{R A J}$ for fracture and variable amplitude loading

\section{Summary and Conclusions}

This paper gives an overview about the new FKM guideline. The guideline provides a recipe for calculations of fatigue lives for notched structures of steel and aluminium alloy under constant or variable amplitude loadings. The guideline presumes a crack initiation criteria $a_{\text {end }}=0.5 \mathrm{~mm}$ for all structures independent of experimental conditions. Because of this independence the accuracy between the experimental and calculated fatigue lives differs, which is similar to observations in the literature. A simple concept to calculate the fatigue live for fracture based on the calculations for crack initiation was shown. This concept shows a good accordance with experimental results even without a crack growth simulation.

\section{Acknowledgement}

The authors expresses their sincere gratitudes to the German Federal Ministry of Economics and Energy (Bundesministerium für Wirtschaft und Energie, BMWi) for financial support via AiF (Arbeitsgemeinschaft industrieller Forschungsvereinigungen „Otto von Guericke“ e.V.) of the research project „Rechnerischer Bauteilfestigkeitsnachweis unter expliziter Erfassung nichtlinearen Werkstoff-Verformungsverhaltens “ under the IGF project no. $17.612 \mathrm{~N} / 1$.

\section{References}

1. R. Rennert, E. Kullig, M. Vormwald, A. Esderts, D. Siegele, Analytical strength assessment of components made of steel, cast iron and aluminum materials in mechanical engineering, 6 (VDMAVerlag, Frankfurt, 2012)

2. N. Dowling, Comprehensive structural integrity, 4, 77 (2003)

3. W. Ramberg, W. Osgood, Technical Note No. 942 (1943)

4. G. Masing, Proc. of the 2nd Int. Congress of Applied Mechanics, 332 (1926)

5. M. Wächter, Zur Ermittlung von zyklischen Werkstoffkennwerten und Schädigungsparameterwöhlerlinien (TU Clausthal, 2016)

6. T. Seeger, A. Beste, Zur Weiterentwicklung von Näherungsformeln für die Berechnung von Kerbbeanspruchungen im elastisch-plastischen Bereich (Düsseldorf, 1977)

7. T. Seeger, A. Beste, H. Amstutz, ICF4, (Waterloo (Canada) 1977)

8. H. Neuber, Trans. ASME J. Appl. Mech., 28, 544 (1961)

9. T. Seeger, Betriebsfestigkeit auf Grundlage örtlicher Beanspruchungen, 3 (2016)

10. U. H. Clormann, T. Seeger, Der Stahlbau, 55 (3), 65 (1986)

11. M. Fiedler, M. Wächter, I. Varfolomeev, M. Vormwald, A. Esderts, Rechnerischer Bauteilfestigkeitsnachweis unter expliziter Erfassung nichtlinearen WerkstoffVerformungsverhaltens, AiF-Projekt Nr. 17612 (Frankfurt, 2015)

12. K. Smith, P. Watson, T. Topper, Journal of Materials, 5 (4), 767 (1970)

13. J. Bergmann, Zur Betriebsfestigkeitsbemessung gekerbter Bauteile auf der Grundlage der örtlichen Beanspruchungen (TU Darmstadt, 1983)

14. M. Vormwald, Anrisslebensdauervorhersage auf Basis der Schwingbruchmechanik für kurze Risse ( TU Darmstadt, 1989) 
15. M. Vormwald, International Journal of Fatigue, 82, $80(2016)$

16. M. Vormwald, Procedia Engineering, 101 (C), 534 (2015)

17. J. C. Newman, ASTM STP 748, 53 (1981)

18. F. Ellmer, A. Esderts, K.-G. Eulitz, K. Hinkelmann, Datenbank und Auswertsystem Betriebsfestigkeit, FKM-Vorhaben Nr.288, 313 (2011)

19. J. Tölle, H. Schmidt, FAT-Schriftenreihe, 221 (2009) 